\title{
ШІЕКСПИРОСФЕРА
}

DOI: $10.17805 / g g z .2017 .6 .4$

\section{Шекспир в современной русской культуре: национальное и глобальное"}

\author{
Б. Н. Гайдин \\ Московский гуманитарный университет
}

В статье представлена конщепџия проекта, задачей которого является изучение влияния творчества У. Шекспира на современную русскую культуру. Особое внимание уделено анализу специфики отечественной рецепции шекспировского наследия в XX-XXI вв. во взаимосвязи национального и глобального.

В этом отношении небезынтересно проследить, как в России отмечались шекспировские юбилеи в 1864, 1914, 1939, 1964 и 2014 г. Эти сведения дают возможность представить отечественную шекспиросферу в исторической перспективе и сделать некоторые выводы о роли Шекспира в современной культуре России. Автор рассматривает некоторые тенденции, характерные для апроприации шекспировского творчества в нашей стране в ХX-XХІ столетиях.

Ключевые слова: У. Шекспир; Шекспир в России; Шекспир в СССР; юбилеи Шекспира; шекспировские юбилеи; современная культура; начиональная культура; мировая культура; массовая культура; рещепция; апроприация; шекспиризачия; шекспиризм; глобализачия; национальная идентичность; постсоветские переводы Шекспира

\section{Shakespeare in Contemporary Russian Culture: The National and Global}

\author{
B. N. Gaydin \\ Moscow University for the Humanities
}

The article presents the concept of the project aimed at studying the influence of W. Shakespeare's oeuvre on contemporary Russian culture. A special at-

\footnotetext{
* Статья подготовлена в рамках проекта «Шекспир в современной русской культуре: национальное и глобальное», осуществляемого при поддержке Совета по грантам Президента РФ (МК-1182.2017.6).

The article was prepared within the framework of the project "Shakespeare in Contemporary Russian Culture: The National and Global" with support from the Council for Grants of the President of Russian Federation (MK-1182.2017.6).
} 
tention is paid to the analysis of specific features in the Russian reception of the Shakespearean legacy in the 20th-21st centuries in the interrelation of the national and global.

In this respect, it is quite significant how people celebrated the anniversaries of Shakespeare's birth in Russia in 1864, 1914, 1939, 1964 and 2014. These observations give an opportunity to present the Russian Shakespearean sphere in its historical perspective and to draw some conclusions on the role of Shakespeare in contemporary culture of Russia. The author considers some tendencies typical for the appropriation of Shakespeare's works in Russia in the 20th-21st centuries.

Keywords: W. Shakespeare; Shakespeare in Russia; Shakespeare in the USSR; anniversaries of Shakespeare's birth; Shakespearean jubilees; contemporary culture; national culture; world culture; mass culture; reception; appropriation; Shakespearisation; Shakespeareanism; globalization; national identity; postSoviet translations of Shakespeare

\section{ВВЕДЕНИЕ}

В настоящее время наблюдается высокий интерес мирового шекспироведения к проблеме рецепции творчества У. Шекспира в рамках национальных культур. Этот факт легко подтверждается тем количеством научных исследований и критических работ по данной тематике, которые ежегодно выходят в свет, а также названиями научных конференций, конгрессов, семинаров, фестивалей и т. п., постоянно проводимых в различных уголках мира.

Исследователи пытаются осмыслить происходящие процессы в «котле» национальных культур, которые испытывают колоссальное влияние различных тенденций, характерных для современной эпохи постглобализма. Фигура Шекспира давно превратилась в символ глобального влияния западноевропейской культуры на другие культурные миры. Однако, с другой стороны, в рамках национальных культур возникает феномен «другого Шекспира» «своего Шекспира». Армения, Бразилия, Германия, Индия, Италия, Испания, Китай, Польша, Россия, Франция, ЮАР, Япония - вот далеко не полный список стран, в которых Шекспир обрел «второй дом».

В библиографической базе данных «Мировая шекспировская библиография онлайн» (World Shakespeare Bibliography Online; www.worldshakesbib.org) можно найти большое количество научных работ, посвященных проблематике изучения «национальных Шекспиров» (national Shakespeares) или «местных / других Шекспиров» (native / local / other Shakespeares) ${ }^{1}$, а также феномена «глобального / всемирного Шекспира» (global /

${ }^{1}$ См., например: Dobson, 1992; Shakespeare in the New Europe, 1994; Shakespeare: World Views, 1996; Shakespeare and Ireland: History, Politics, Culture, 1997; Shakespeare and National Culture, 1997; Foreign Accents: Brazilian Readings of Shakespeare, 2002; Shakespeare 
universal Shakespeare $)^{2}$. Представляется, что число таких работ будет в ближайшие десятилетия только расти.

То, какое отражение получает шекспировское наследие в той или иной национальной культуре, во многом характеризует ее состояние и перспективы развития. Проведенное нами раннее исследование феномена неошекспиризации в современной художественной культуре выявило значительное количество отечественных художественных произведений (пьесы, театральные и литературные переделки, романы, повести, рассказы, балеты, оперы, фильмы, мюзиклы и т. д.), в которых в той или иной степени ощущается шекспировское влияние (Гайдин, 2013a; 2014ab). Значительная их часть заслуживает пристального изучения и осмысления. Представляется, что более глубокий анализ русской современной культуры в данном контексте позволит выявить некоторые особенности ее развития и более глубоко понять специфику социокультурных процессов в изменяющейся России.

За последнее столетие различные тенденции мировой культуры значительно видоизменили художественный процесс как таковой. Но парадокс современной культуры заключается в сопряжении ультрасовременного концептуального искусства с возрождением классических традиций, среди которых особое место заняла шекспировская традиция. Наше научное исследование призвано не только получить новые данные о рецепции творчества Шекспира в нашей стране в XX-XXI столетиях, но и познакомить иностранных специалистов с лучшими и наиболее самобытными примерами влияния британского драматурга на современную культуру России.

Как известно, в русскую культуру имя Уильяма Шекспира вошло только спустя 132 года после ухода драматурга из жизни: в 1748 г. была издана брошюра «Две эпистолы» русского поэта и драматурга А. П. Сумарокова, в которой он упомянул о «непросвещенном» Шекспире как одном из известных литераторов минувших эпох (эпистола «О стихотворстве») (Сумароков, 1748a: 9; 1957: 117; см., например: Клейн, 1993; Захаров, 2008ab), отметив в примечаниях, что в его сочинениях есть и хорошее, и плохое (Сумароков, 1748b: 28). С тех пор интерес к личности драматурга и его наследию в России переживал разные периоды. Были и времена большого интереса, когда одним

and Spain, 2002; India's Shakespeare: Translation, Interpretation, and Performance, 2005; Kishi, Bradshaw, 2005; Orkin, 2005; World-Wide Shakespeares: Local Appropriations in Film and Performance, 2005; Native Shakespeares: Indigenous Appropriations on a Global Stage, 2008; The Shakespearean International Yearbook, 2008; Huang, 2009; The Shakespearean International Yearbook, 2012; Performing Shakespeare in India: Exploring Indianness, Literatures and Cultures, 2016; Shakespeare, Italy, and Transnational Exchange: Early Modern to Present, 2017.

${ }^{2}$ См., например: Burnett, 2007; Global Shakespeare, 2012; Huang, 2013; Shakespeare on the Global Stage: Performance and Festivity in the Olympic Year, 2015; South African Essays on 'Universal' Shakespeare, 2016. 
за другим появлялись новые переводы, а шекспировские постановки не сходили с театральных подмостков, были и годы некоторого «забвения».

Определенное представление об истории рецепции творчества Шекспира в русском культурном тезаурусе можно получить, изучив материалы о том, как в России отмечали юбилеи со дня рождения драматурга в 1864,1914 , 1939, 1964 и 2014 г.

\section{ШЕКСПИРОВСКИЕ ЮБИЛЕИ В РОССИИ}

В 1864 г. планировались широкие торжества в честь трехсотлетнего юбилея поэта, но из-за отрицательного отношения императора к этой идее масштаб празднований был существенно более скромный. Российскобританские отношения тех лет были напряженными, поэтому власть имущие посчитали, что негоже отдавать честь «национальному поэту» недружественной державы. Вместо официальных празднований на сцене Императорского театра торжества были проведены главным образом в частном порядке. Тем не менее, даже небольшие вечера и собрания различных литературных и театральных сообществ оставили после себя заметный след как в мемуарах и публицистике, так и в художественной литературе тех лет (см., например: Левин, 1965: 410-413; Ратников, 2011).

В 1914 г. страна стояла на пороге мировой войны, в обществе царили предчувствия смуты и больших перемен, и каких-либо широких торжеств не было. По крайней мере, отражения в печати они не получили, поскольку интерес к шекспировскому наследию был в то время небольшим. Как писал М. Б. Загорский, «последние годы перед революционными бурями и вступлением страны в новую эпоху своего существования Шекспир почти вышел из сферы внимания печати и критики. Еще иногда возникали шекспировские спектакли, но они не находили внимательного отношения у критиков...» (Загорский, 1947: 100). Драматург и литературный критик отмечал, что в журнале «Театр и искусство» были опубликованы лишь фотографии актеров, прославившихся исполнением ролей в постановках шекспировских пьес, а также «вздорная и легкомысленная статья» историка театра, критика Н. Н. Долгова (Долгов, 1914) ${ }^{3}$, который утверждал, «что после Мочалова русская сцена рассталась с Шекспиром» (цит. по: Загорский, 1947: 100-101). По мнению Загорского, такая «вопиющая неправда» и «клевета», которая вычеркнула значительную часть истории шекспировских постановок в России (Г. Н. Федотова, А. П. Ленский), могла быть напечатана «в лучшем тогдашнем театральном журнале лишь потому, что в эти последние годы царской

\footnotetext{
${ }^{3}$ Интересно, что Н. Н. Долгов известен главным образом как исследователь жизни и творчества «русского Шекспира» А. Н. Островского. См.: Шнеер, 1963; Чернышова: Электронный ресурс.
} 
России никого из русских критиков, за редким исключением, уже не волновали шекспировские темы» (там же: 101).

Спустя четверть века, в 1939 г., интерес к драматургу уже вновь был достаточно большим. Советские театральные деятели, критики, переводчики вновь активно обращались к его пьесам, пытаясь найти применение «старой доброй классике» в новых общественно-политических условиях. Интересные данные на основе архивных материалов приводит И. Н. Лагутина: в год $375-$ летия со дня рождения Шекспира в советской прессе появилась целая серия статей и заметок о писателе и его месте в современной советской культуре. К примеру, в газете «Советское искусство» за 21 апреля 1939 г. можно найти сразу две полосы, посвященные «великому гуманисту» (Лагутина, 2017а: 316-317; см. также: Лагутина, 2017b). Хорошим примером того, каков был официальный подход к пониманию шекспировского наследия в СССР тех лет, является опубликованная в этом номере статья «Задача художника» театрального художника Н. А. Шифрина ${ }^{4}$. В ней «не только определялось место Шекспира в пантеоне классических писателей (рядом с Пушкиным), не только обозначался один единственный подход к интерпретации его творчества — “подлинность”, найденная “в борьбе” с идеализмом и формализмом, но и задавался сам тон, которым следует говорить о Шекспире, — язык политической борьбы за новые советские ценности...» (Лагутина, 2017a: 317).

Опубликованные материалы «последовательно выстраивали образ великого английского драматурга, обозначая узловые моменты советского присвоения Шекспира» (там же). По тому количеству статей, которое вышло 23 апреля 1939 г. в центральных, областных, районных, заводских и т. д. газетах, можно не сомневаться, что к юбилею готовились заранее и очень тщательно. Конечно, такой размах торжеств был бы невозможен, если бы все это не было согласовано на самом высоком правительственном уровне. Примерно к этому времени в умах политических деятелей окончательно созрела идея о необходимости использования наследия мировых классиков для развития новой советской культуры, которая естественно выступала рупором официальной коммунистической идеологии.

Шекспировский юбилей 1964 г. пришелся на самый конец так называемой хрущевской оттепели, которая началась после смерти И. В. Сталина в 1953 г. Как отмечает Ю. В. Аксютин, «критика “культа личности и его последствий” оказали огромное влияние на советскую политическую систему и

\footnotetext{
${ }^{4}$ Н. А. Шифрин был художником-постановщиком следующих шекспировских спектаклей: «Укрощение строптивой» в Центральном театре Красной Армии (1938), «Как вам это понравится» в театре им. М. Н. Ермоловой (1940), «Сон в летнюю ночь» на сцене Центрального театра Красной Армии (1941), «Виндзорские насмешницы» в Театре им. Моссовета (1957). См.: Шифрина, 1975: 216.
} 
общественную жизнь. <..> Однако начатый тогда процесс либерализации оказался непоследовательным, недостаточно широким и глубоким, он не получил должной поддержки ни общества, ни элиты. Открытое, на грани войны противостояние с Западом хоть и смягчилось в известной степени, однако международная разрядка не стала абсолютной и то и дело отравлялась рецидивами дипломатической и даже военной напряженности» (Аксютин, 2010: 5-6). 14 октября 1964 г. Н. С. Хрущев был снят с должности Первого секретаря ЦК КПСС. Тем не менее, он успел оставить свой «след» и в истории «русского Шекспира».

К шекспировскому юбилею 1964 г. в СССР начали готовиться заранее. В 1957-1960 гг. было издано новое полное собрание сочинений Шекспира на русском языке в 8 томах (Шекспир, 1957-1960), для которого специально были подготовлены новые переводы и отредактированы старые. Это было второе советское полное собрание сочинений британского драматурга. В предисловии от редакции было указано, что отличие от первого издания под редакцией С. С. Динамова и А. А. Смирнова, вышедшего в 1936-1950 гг. (Шекспир, 1936-1950), «при сохранении той же точности в переводах, недостаточно соблюдавшейся в дореволюционных изданиях, в нем обращено особое внимание на художественную выразительность переводов, в частности, очень важную при использовании их для театральных постановок» (От редакции, 1957: 5).

К четырехсотлетию со дня рождения Шекспира вышли в свет фундаментальные научные монографии и сборники статей, затрагивающие различные проблемы шекспироведения: «Шекспир: его герой и его время» (Урнов М., Урнов Д., 1964), «Вильям Шекспир: К четырехсотлетию со дня рождения. 1564-1964. Исследования и материалы» (Вильям Шекспир ... , 1964), «Шекспир в мировой литературе» (Шекспир в мировой литературе, 1964), «Шекспир и музыка» (Шекспир и музыка, 1964). Также был опубликован библиографический указатель «Шекспир: библиография русских переводов и критической литературы на русском языке, 1748-1962» (Шекспир ... , 1964).

Готовилось и большое количество театральных постановок, программа обещала быть насыщенной, но вновь вмешались власть имущие. Первый секретарь ЦК КПСС Н. С. Хрущев в своей речи на встрече с интеллигенцией пожурил театральных режиссеров, что вместо современных пьес, отражающих будни трудового советского народа, они ставят классические пьесы: «Как ни придешь в МХАТ, там все шотландскую королеву на эшафот ведут. Зачем вам эта Мария Стюарт? Снимите вы ее, уберите с афиши. Старик 
Шекспир на нас не обидится!» (цит. по: Бартошевич, 2014a: 225) В результате никто не стал перечить лидеру страны и указывать ему, что «Марию Стюарт» написал Ф. Шиллер, а не Шекспир. Команда была дана и многие шекспировские постановки были сняты с репертуара. Закончилось все тем, что юбилей отметили в Большом театре «длинными и скучными докладами, ровно ничем не отличавшееся от всех прочих казенных толковищ» (там же).

Советские власти в то время по-прежнему жестко контролировали область культуры, могли так или иначе влиять на писателей, режиссеров и других деятелей культуры, давать или не давать возможность поставить спектакль, снять фильм или издать книгу. Шекспир в этот период вновь не приветствовался на высшем уровне, тем не менее Г. М. Козинцев смог снять «Гамлета», вышедшего на экран в 1964 г. Других фильмов к юбилею снято не было, хотя такие планы были. Так, известно, что у режиссера С. Н. Колосова, снявшего имевший успех фильм «Укрощение строптивой» в 1961 г., была задумка экранизировать пьесу «Как вам это понравится», где роль Розалинды должна была сыграть его супруга Л. И. Касаткина. Режиссер подготовил сценарий и дважды подавал его на утверждение начальству. К сожалению, идея осталась невоплощенной из-за чинимых административных барьеров. Окончательно от нее пришлось отказаться из-за упоминавшийся выше речи Н. С. Хрущева (Колосов, Касаткина, 2005: 174-176). Сам Колосов так вспоминал ответ генерального директора «Мосфильма» В. Н. Сурина на его вопрос, почему ему отказали в оплате за уже готовый сценарий: «Звонит мне заведующий сектором кино ЦК, говорит: 'В плане 'Мосфильма' много западных авторов, например, Шекспир. Одного Шекспира мы уже делаем - Козинцев на 'Ленфильме' 'Гамлета' снимает. А зачем еще? Тем более, режиссер молодой, пусть современную тему поднимает... Товарищ Колосов газеты читает? Материалы исторической встречи товарища Хрущева с писателями усвоил? Западные авторы сейчас не нужны"» (там же: 176).

Запретить Шекспира и полностью вычеркнуть его из людской памяти, конечно, было, конечно, невозможно. Небезынтересно в этом отношении проследить судьбу Шекспира и его образов в оригинальных произведениях тех лет, причем не только известных писателей, поэтов и драматургов, но и малоизвестных авторов. Например, в 1963 г. в журнале «Юность» были

\footnotetext{
${ }^{5}$ В архивах можно найти еще как минимум одно высказывание Н. С. Хрущева с отсылкой к Шекспиру. В мае 1962 г. во время пребывания советской делегации в Болгарии он заявил: «Ведь еще Шекспир говорил, что мир должен быть населен. А наш социалистический мир, где все делается для человека, тем более должен быть населен здоровыми и счастливыми людьми. Мы желаем счастья и успехов восьмимиллионному болгарскому гражданину, как и всем людям вашей замечательной страны. Пусть он радуется щедрому болгарскому солнцу...» («Правда», 1962, 20 мая). Цит. по: СССР и Болгария - навеки вместе ..., 1962: 117.
} 
опубликованы стихотворения рабочего каменщика, учителя и поэта из г. Дивногорска (Красноярский край) Владлена Николаевича Белкина (в журнале указан как Владилен; род. 6.01.1931, с. Щербакуль, Омская область). В одном из них упоминается Шекспир, творчество которого, видимо, оказало на поэта некоторое влияние:

Кем я был?
Свинопасом.
Ел картошку «в мундире».
Я к созвездиям рвался,
А пьянел от Шекспира.
Я в рабочей рубахе
Выходил на перрон.
Я в эпоху врубался
Топором и пером...
(Белкин, 1963: 3)

Как писал поэт и журналист А. И. Безыменский, «это стихи рабочего человека. В них трепещет его жизнь, кипят его чувства, его думы и мечты. Рабочая душа светится в темах произведений поэта, в их направленности, проявляется и в идее стихов и в поэтических деталях» (Безыменский, 1963: 2). В этом произведении Шекспир выступает в качестве символа мировой культуры, к которой стремился простой советский человек.

В 2014 г. весь мир отмечал 450-летие со дня рождения У. Шекспира. В России не было недостатка в новых постановках. Например, только в Москве одновременно шли четыре «Гамлета», что, скорее всего, стало своеобразным мировым рекордом. А. В. Бартошевич отметил также большое число постановок «Ромео и Джульетты» по всей стране (Бартошевич, 2014b: 29). Во многих российских городах были организованы научные конференции, литературные чтения, конкурсы и другие мероприятия, посвященные юбилею драматурга.

14-18 сентября 2014 г. в Москве проходила самая крупная за всю историю отечественного шекспироведения конференция - XXV Шекспировские чтения, которые были посвящены теме «Шекспир в русско-английском культурном диалоге» (см.: Итоги XXV Шекспировских чтений 2014..., 2014: Электронный ресурс; XXV Шекспировские чтения 2014 ..., 2014). Также появился ряд новых изданий шекспировских пьес (Шекспир, 2014abcdefg; Coнеты Шекспира, 2014) и научных монографий, в которых рассмотрены различные проблемы шекспировских штудий (Бартошевич, 2014c; Федорова, 2014; Чекалов, 2014; и др.).

Уже в 2015 г. в издательстве «Просвещение» вышла книга «Уильям Шекспир. Энциклопедия» под редакцией доктора филологических наук, 
профессора И. О. Шайтанова (Уильям Шекспир. Энциклопедия, 2015). Энциклопедия стала лауреатом Национальной премии «Лучшие книги и издательства года - 2015» в номинации «Издательские проекты» (Национальная премия ..., 2016: Электронный ресурс). К сожалению, тираж издания составил всего 50 экземпляров (Уильям Шекспир: энциклопедия (подарочное издание): Электронный ресурс). В этом же году в Москве и Санкт-Петербурге были проведены семь тематических заседаний международного научного семинара «Шекспир в междисциплинарных гуманитарных исследованиях» (Макаров, Захаров, Гайдин, 2015: Электронный ресурс), по итогам которых была издана коллективная монография (Шекспир в междисциплинарных ... , 2015).

В 2016 г. мы также стали свидетелями большого числа культурных и научных событий, посвященных 400-летию смерти великого драматурга. К примеру, получил развитие проект TheatreHD, в рамках которого в 50 городах России, Украины и Казахстана в кинотеатрах показывали популярные постановки шекспировского театра «Глобус», Королевского национального театра, центра «Барбикан», Метрополитен опера, Большого театра и др. 21 апреля 2016 г. в Государственной Третьяковской галерее открылась выставка «От Елизаветы до Виктории. Английский портрет из собрания Национальной портретной галереи, Лондон». Из британской столицы был привезен один из самых известных портретов Шекспира — «Чандосовский портрет», написанный приблизительно в 1600-е годы и приписываемый кисти Джона Тейлора (John Taylor). На Филевской линии московского метрополитена курсировал тематический поезд, посвященный творчеству драматургу и персонажам его произведений. Также состоялись фестиваль Shakespeare Lives, различные шекспировские конкурсы и олимпиады, были опубликованы несколько онлайн-курсов, видеолекций, появились новые переводы шекспировских произведений. Также были изданы пятый номер журнала «Иностранная литература» за 2016 год, который был целиком посвящен 400-летию со дня смерти писателя, сборник «Фантастический Шекспир» (Фантастический Шекспир, 2016), академическое двуязычное издание «Сонетов» (Шекспир, 2016; см. также: Макаров и др., 2017; подробнее о событиях 2016 года см.: Захаров, Гайдин, Макаров, 2016; Макаров, Захаров, Гайдин, 2016).

Также были организованы и проведены несколько научных конференций, заседаний и секций, посвященных британскому драматургу. Самым крупным мероприятием стала XXVI Международная научная конференция «Шекспировские чтения 2016: 400 лет бессмертия поэта» (Москва, 26-29 сентября 2016 г.) (см. подробнее: Итоги XXVI Международной научной конференции ..., 2017; см. также сборники аннотаций докладов: XXVI Шекспировские чтения 2016 ..., 2016; 26th Shakespeare Readings 2016 ..., 2016). 
Таким образом, можно с уверенностью сказать, что для определенной части населения современной России Шекспир - важная культурная константа. Большинству же носителей русской культуры шекспировское наследие известно обычно главным образом в виде вечных образов (Гамлет, Ромео и Джульетта, Отелло), крылатых выражений («Быть или не быть?», «Коня! Коня! Полцарства за коня!», «Чума на оба ваши дома!» и др.), различных цитат из кинофильмов (к примеру, «Не пора ли, друзья мои, нам замахнуться на Вильяма, понимаете, нашего Шекспира?» из кинокомедии «Берегись автомобиля» Э. А. Рязанова).

Главный интерес представляет, конечно, не количество спектаклей, фильмов, книг, концертов и конференций, а их содержание. В своем исследовании мы представим основные тенденции, которые, на наш взгляд, характерны для рецепции шекспировского наследия в современной отечественной культуре. Мы рассмотрим переводы произведений Шекспира и их судьбу на театральных подмостках и на экране, самые значимые театральные постановки, различные литературные адаптации, переделки, вариации, так или иначе связанные с наследием «Эйвонского Лебедя», а также интерпретации шекспировских образов, сюжетов, мотивов, крылатых слов и выражений в отечественном кино, телевидении и радио, а также в музыке и живописи.

Конечно, невозможно охватить все вышеуказанное даже в общих чертах в рамках одной статьи. Поэтому далее мы сформулируем несколько тезисов о постсоветских шекспировских переводах и их месте в современной отечественной культуре.

\section{ПОСТСОВЕТСКИЕ ШЕКСПИРОВСКИЕ ПЕРЕВОДЫ}

Известно, что каждое новое поколение переводчиков пытается передать шекспировские строки на русском языке в соответствии с духом своей эпохи. В XX-XXI вв. отечественный культурный тезаурус пополнился большим количеством переводов шекспировских пьес, поэм и сонетов. Если «классические» русские переводы признанных мастеров художественного перевода советского периода достаточно хорошо изучены (хотя есть еще некоторые лакуны), то более новые переводы еще ждут своих критиков и исследователей. За последние три десятилетия с развитием книжного рынка и особенно Интернета появилось значительное количество новых переводов Шекспира разного рода и качества ${ }^{6}$.

\footnotetext{
${ }^{6}$ В настоящее время при поддержке РФФИ ведется работа над проектом «Программа сравнительного тезаурусного анализа русских переводов произведений У. Шекспира» (проект № 17-04-12038в; www.shakespearecorpus.ru). Переводы пьес, поэм и сонетов Шекспира на русский язык впервые будут представлены в визуализированной среде на базе платформы Version Variation Visualization (VVV). На сайте будет доступен ряд ин-
} 
Некоторые переводчики стремятся передать слова Шекспира еще более точно, чем их предшественники в XIX-XX вв. и при этом соблюсти принцип эквилинеарности (например, И. В. Пешков, Н. Н. Самойлов и др.). Другие, напротив, предлагают довольно «вольные» переводы, которые, на наш взгляд, скорее следует рассматривать как литературные или театральные адаптации (В. Р. Поплавский, А. Ю. Чернов и др.); обычно они ставятся либо самими переводчиками, либо специально заказываются режиссерами. Есть и те, которые предлагают некий синтез и пытаются соблюсти баланс между точностью и удобочитаемостью (В. З. Ананьин, Г. М. Кружков, Ю. И. Лифшиц, А. В. Флоря и др.). Отметим, что интерес современных постановщиков и режиссеров к новым переводам небольшой. Большинство спектаклей идут в классических переводах (М. Л. Лозинский, Б. Л. Пастернак, А. Д. Радлова), иногда режиссеры просто делают нарезку из классических переводов и даже дополняют их собственными вариантами переводов отдельных строк (например, «Гамлет» в постановке B. В. Фокина, который использовал драматургическую адаптацию В. Н. Леванова). Это характерно не только для театра, но и для кино (например, «Гамлет ХХІ век» Ю. В. Кары; см., например: Гайдин, 2013b).

Не секрет, что уже не первое десятилетие не только в России, но и в других странах вербальное уступает позиции визуальному. Текст уже не первое десятилетие уходит на «второй план». Это во многом характерно и применительно к судьбе шекспировских текстов. Очевидно, что большинство представителей современного поколения российских режиссеров во многом не испытывает пиетета перед текстом Шекспира. Никто не запрещает им использовать наследие Шекспира так, как представляется им наиболее актуальным и целесообразным.

Не так часто кто-то из них рискует использовать какой-то новый перевод. Таким образом, новые версии возникают, но большого интереса к ним со стороны театрального сообщества не наблюдается. Можно предположить, что виной тому тот факт, что большинство режиссеров просто не имеют финансовых ресурсов, чтобы оплачивать труд переводчиков. Но дело, конечно, не только в этом. Все же большинство предпочитает работать с проверенными годами текстами. Конечно, можно «сэкономить», использовав переводы, находящиеся в общественном достоянии, но можно сделать и своеобразное «попурри» (скорее всего, и в этом случае никаких выплат переводчикам и их наследникам уже не предусмотрено).

Спор о том, нужны ли нам новые переводы всем известных пьес Шекспира, вряд ли когда-нибудь закончится. Даже в англоязычных странах все больше

струментов для сравнения переводов с англоязычными оригиналами и между собой. О возможностях платформы см. подробнее: Cheesman, 2015; Чизман, 2015; Гайдин, 2015. 
голосов звучит о том, что новым поколением британцев, американцев, австралийцев и других носителей языка Шекспира необходимы пересказы «устаревшего» драматурга на современный английский язык ${ }^{7}$. Для русскоязычного же мира работы переводчиков М. Л. Лозинского, Б. Л. Пастернака, А. Д. Радловой, С. Я. Маршака и других мастеров пока что не превратились в архаичные и непригодные для современной сцены. Они вполне еще не исчерпали своего потенциала.

\section{ЗАКЛЮЧЕНИЕ}

Таким образом, уже более 265 лет творчество Шекспира обретает новые формы и содержание на почве русской культуры. В трудах литературоведов, театроведов, киноведов, музыковедов, культурологов, философов культуры и т. д., в СМИ и Интернете можно найти упоминания большого количества русскоязычных оригинальных литературных или музыкальных произведений, различных театральных постановок, кино- и телефильмов, в которых содержится разнообразный «шекспировский» материал - от широкого использования образов и сюжетов до цитирования отдельных строк поэта и драматурга, упоминания имени Шекспира и т. д. Если подобные феномены культуры XVIII-XIX вв. уже нашли довольно подробное отражение в научных исследованиях, то значительная часть примеров, относящихся к XX-XXI вв., никогда прежде не подвергалась подробному анализу.

В качестве эмпирического материала для нашего исследования служат произведения как известных во всем мире русскоязычных писателей, поэтов, режиссеров, композиторов, авторов-исполнителей, художников и т. д., так и творчество менее знаменитых представителей отечественной культуры. Предполагается рассмотреть основные три периода ее развития: дореволюционный (1900-1917 гг.), советский (1918-1991 гг.), постсоветский (1991 — наши дни). Это должно позволить представить детальный анализ разного рода примеров рецепции творчества У. Шекспира в тезаурусах деятелей отечественной художественной культуры XX-XXI столетий и выявить характерные для разных этапов ее развития тенденции и признаки.

Художественно-эстетические принципы-процессы неошекспиризации и неошекспиризма рассматриваются нами в аспекте диалога культур на примере русскоязычных культурных феноменов, носящих как «особый национальный колорит», так и характер «всемирности», при котором националь-

\footnotetext{
${ }^{7}$ Примером этого является, например, трехлетний проект «Продолжай играть! 36 драматургов переводят Шекспира» (Play On! 36 Playwrights Translate Shakespeare), организованный устроителями Орегонского шекспировского фестиваля в 2015 г. (см.: About Play On!: Электронный pecypc; Oregon Shakespeare Festival's Play On! ..., 2015: Электронный ресурс).
} 
ные признаки уже не столь легко выявить. Детальный анализ и сравнение классических и современных переводов, постановок, экранизаций, различных переделок шекспировских пьес, поэм и сонетов может позволить судить о данных явлениях в широком контексте и очертить дальнейший ход исследования. На конкретном материале будет показано, каким образом в ходе влияния различных национальных и глобальных процессов изменялся и продолжает изменяться характер различных течений, школ, жанров, стилей и направлений, персональных моделей и т. п., которые так или иначе испытали влияние Шекспира внутри отечественной культуры в разные периоды современной истории нашей страны.

Последняя фундаментальная работа о месте Шекспира в русской культуре вышла более 50 лет назад. Причем коллективная монография под редакцией академика М. П. Алексеева «Шекспир и русская культура» (Шекспир и русская культура, 1965) охватывает период с первых упоминаний Шекспира в России лишь до революции 1917 г. Безусловно, существуют исследования, посвященные изучению влияния Шекспира на творчество отдельных отечественных авторов, композиторов, режиссеров и т. д. XX-XXI вв. и/ли охватывающие более короткие периоды истории современной культуры России. Наша работа «Неошекспиризация в современной художественной культуре» (Гайдин, 2014b) затрагивает многие аспекты данного исследования, однако, во-первых, в ней анализируются примеры самых разных культур, во-вторых, некоторые вопросы требуют дальнейшего осмысления. Задача выявить особенности рецепции шекспировского творчества в современной отечественной художественной культуре, насколько нам известно, до сих пор еще не ставилась.

Основные научные методы, применяемые в исследовании: историкотеоретический и тезаурусный подходы к изучению литературы, литературного процесса, творчества писателей; сравнительно-исторический и типологический анализ творчества, поэтики Шекспира и современных писателей; герменевтический подход к интерпретации текста.

В нашем исследовании мы ставим перед собой задачу проанализировать различные концепции «национальных Шекспиров» (National Shakespeares) и феномена «глобального Шекспира»(Global Shakespeare), предложенные учеными разных стран, школ и направлений. Их идеи буду транспонированы на конкретные примеры современной отечественной художественной культуры, в которых нашли отражение шекспировское наследие, культ Шекспира, шекспировская индустрия и т. д.

В данной статье мы изложили общую концепция исследования. Проект должен завершиться публикацией итоговой монографии, рабочий план которой выглядит следующим образом: 
- Введение;

- Глава I. Шекспир в России XX-XXI вв.;

- Глава II. Шекспир в дореволюционной России (1900-1917);

- Глава III. Шекспир в советскую эпоху (1918-1991);

- Глава IV. Шекспир в Новой России (1991 - наше время);

- Заключение.

Глава «Шекспир в России XX-XXI вв.» будет посвящена теоретикоисторической разработке темы исследования. Будут подробно изучены рецепция Шекспира в современной отечественной культуре, процессы неошекспиризации и неошекспиризма в культурном тезаурусе России. Участники проекта планируют подробно проанализировать наиболее самобытные и интересные литературные, театральные, музыкальные, кинематографические и т. д. произведения (дореволюционные, советские и постсоветские), сопоставляя их с примерами рецепции шекспировского наследия других эпох и в иных национальных культурах, выявить их национальные и глобальные черты, а также основные закономерности развития русской культуры XX-XXI вв. в данном контексте. Результаты исследования будут опубликованы как в виде обзорно-теоретических статей в научных журналах, входящих в различные наукометрические индексы, так и в виде отдельных энциклопедических статей о писателях, драматургах, поэтах, режиссерах, композиторах, авторах-исполнителях и т. д. и их произведениях в Электронной энциклопедии «Мир Шекспира» (www.world-shake.ru). Часть из них (в частности, освещающие наиболее самобытные примеры неошекспиризации и неошекспиризма в русской культуре) будет переведена на английский язык и опубликована в англоязычной версии данной шекспировской энциклопедии, работа над которой ведется коллективом Института фундаментальных и прикладных исследований МосГУ, членами Шекспировской комиссии РАН, а также приглашенными авторами.

В 2018 г. запланированы сбор и аналитическая обработка материалов по рецепции Шекспира в творчестве Б. Ю. Поплавского, Ю. К. Олеши,
А. А. Ахматовой, И. А. Бродского,
В. С. Высоцкого,
Е. А. Евтушенко,
В. В. Ерофеева,
В. М. Шнейдера,
Л. А. Филатова,
Г. И. Горина, Л. С. Петрушевской, А. Д. Попова и мн. др., в контексте различных постановок и экранизаций и т. п. Коллектив научного проекта продолжит работу над разделами глав «Шекспир в дореволюционной России (1900-1917)», «Шекспир в советскую эпоху (1918-1991)», «Шекспир в Новой России (1991 наше время), в которых будут рассмотрены различные примеры неошекспиризации на примере культурных феноменов, как носящих «особый национальный колорит», так и характерных для мира эпохи глобализации и постглобализации; и др. 
В ходе исследования предполагается выявить и провести подробный анализ примеров творческого переосмысления шекспировского наследия в отечественном культурном тезаурусе, которые возникли в рассматриваемый период. Особое внимание будет уделено изучению национальных и глобальных культурных тенденций в современной отечественной художественной литературе, театре, музыке, кино и телевидении, а также в синтетических видах искусства, в которых так или иначе были использованы образы, цитаты, реминисценций и т. п. из произведений Шекспира, а также образа самого британского драматурга при создании оригинальных художественных произведений.

Второй целью проекта является теоретическое обобщение выявленного эмпирического материала, которое позволит существенно обогатить концепции шекспиризации и шекспиризма в их современных формах и внести свою лепту в изучение мировой шекспиросферы.

Задачей исследования является фундаментальный анализ влияния У. Шекспира на творчество как знаменитых, так и менее известных отечественных писателей, поэтов, режиссеров, актеров, композиторов, музыкантов, художников XX-XXI столетий. Участники проекта ставят пред собой задачу проанализировать их произведения и работы сквозь призму национальных и глобальных социокультурных процессов. Исследование предполагает всестороннее изучение рецепции Шекспира в современной русской художественной культуре, выявление особенностей национальной культуры России и ее диалога с другими культурами в данном контексте.

Некоторые предварительные выводы исследования, полученные в 2017 г.:

1. Большой интерес представляет изучение не только использования шекспировских образов, мотивов, сюжетов, но и судьба переводов цитат из произведений драматурга в сочинениях других писателей, поэтов, драматургов, а также в театральных постановках, фильмах, медийных продуктах и т. д. Многие из них превратились в крылатые выражения. Неточность передачи шекспировского оригинала может способствовать широкому распространению крылатого выражения в культурном тезаурусе. В отличие от афоризмов крылатые слова могут в зависимости от контекста менять смысл, а также иногда подвергаются словесным трансформациям (например, «Коня! Коня! Полцарства за коня!»). В некоторых случаях не всегда возможно доказать, что крылатое выражение является отсылкой к Шекспиру, однако чаще всего нет оснований и для утверждения обратного (ср., например, «Краткость - сестра таланта» (А. П. Чехов) и "Brevity is the soul of wit" («Гамлет», II, 2)). На наш взгляд, оба крылатых выражения, получившие большое распространение в русской культуре в несколько видоизмененном виде, свидетельствуют о большой силе русского национального культурного кода, который 
способен вобрать в себя фразы иностранных авторов, переработать их, придать национальный окрас. Все это, на наш взгляд, никак не контрастируют с шекспировской картиной мира, таким образом, крылатые выражения «Коня, коня! Полцарства за коня» и «Краткость - сестра таланта» можно считать примерами шекспиризма русской культуры (см. подробнее: Гайдин, 2017а, 2018).

2. Было проведено исследование творческой судьбы советского режиссера С. И. Юткевича, изучен его первый опыт обращения к Шекспиру совместно с С. М. Эйзенштейном в качестве художников-постановщиков (спектакль «Макбет» режиссёра В.В.Тихоновича в Центральном просветительском театре). Был осуществлен анализ его фильма «Отелло» (1955) - первой цветной экранизации трагедии венецианского мавра в мире. На наш взгляд, эта киноверсия «Отелло» оказалась в некоторых аспектах непонятной для иностранных зрителей, критиков и киноведов. Во многом она является таковой и для большинства современных российских кинозрителей. Возможно, в этом кроется причина того, что в отличие от шекспировских фильмов Г. М. Козинцева «Гамлет» (1964) и «Король Лир» (1970) работа Юткевича становится предметом исследований западных шекспироведов намного реже (см. подробнее: Гайдин, 2017b).

3. Была затронута проблема определения понятия «мировое кино», охарактеризован характер соединения национального и глобального в «шекспировском кино». Шекспировское наследие может проявляться в кинематографе не только в диалоге режиссера с Шекспиром, но и в полилоге с другими режиссерами, писателями, исследователями, деятелями культуры и искусства, которые внесли свой вклад в национальные традиции рецепции сочинений британского драматурга и поэта (см. подробнее: Гайдин, 2017c).

4. Интерес представляют не только произведения и работы известных авторов, режиссеров, актеров и т. д., в которых можно обнаружить «шекспировский след». Особое значение для более глубокого понимания специфики рецепции Шекспира в современной культуре и ее трансформаций в различные исторические периоды нашей страны приобретают примеры из творчества малоизвестных авторов. Основная их часть не имеет большой художественной ценности, однако именно на этом широком эмпирическом материале можно выявить основные тенденции в рецепции и апроприации шекспировского наследия в массовой культуре. Бурное развитие интернеткоммуникации в России в 2000-2010-х гг. существенно увеличило число доступных для изучения примеров. Также перспективным представляется изу- 
чение так называемых «частных / приватных Шекспиров» в различных ранее недоступных личных дневниках носителей русской культуры ${ }^{8}$

Результаты исследования могут внести свою лепту в развитие теории литературоведения, в целом, и шекспироведения, в частности. Подробное исследование механизмов рецепции творчества Шекспира в культурном тезаурусе России XX-XXI вв. может дать почву для новых открытий в данной сфере, предоставит возможность глубже понять различные социокультурные процессы как прошлого, так и настоящего. Представляется, что проведенное исследование может способствовать интенсификации исследований, посвященных изучению феномена «Русский Шекспир», особенно среди молодых ученых.

\section{СПИСОК ЛИТЕРАТУРЫ}

Аксютин, Ю. В. (2010) Хрущевская «оттепель» и общественные настроения в СССР в 1953-1964 гг. 2-е изд., испр. и доп. М. : Российская политическая энциклопедия (РОССПЭН); Фонд «Президентский центр Б. Н. Ельцина». 622 с.

Бартошевич, А. В. (2014а) Хроника шекспировского года // Знание. Понимание. Умение. № 2. С. 224-235.

Бартошевич, А. В. (2014b) Хроника шекспировского года. Заметки // Вопросы театра. № 1-2. С. 29-40.

Бартошевич, А. В. (2014c) Для кого написан «Гамлет». Шекспир в театре. XIX, XX, XXI... М. : ГИТИС. 635, [1] с.

Безыменский, А. И. (1963) Владлен Белкин // Юность. № 6. С. 2.

Белкин, В. Н. (1963) Кем я был? // Юность. № 6. С. 3.

Вильям Шекспир: К четырехсотлетию со дня рождения. 1564-1964 (1964) : Исследования и материалы / Акад. наук СССР. Ин-т мировой литературы им. А. М. Горького ; [Редколл.: Р. М. Самарин (глав. ред.) и др.]. М. : Наука. 490 с.

Гайдин, Б. Н. (2013а) Неошекспиризация в тезаурусе современной художественной культуры: постановка проблемы // Тезаурусный анализ мировой культуры : сб. науч. трудов. Вып. 27 : Специальный выпуск : Высшее образование для XXI века: X Международная научная конференция. Москва, 14-16 ноября 2013 г. : доклады и материалы. Симпозиум «Тезаурусный анализ мировой культуры» / под общ. ред. Вл. А. Лукова. М. : Изд-во Моск. гуманит. ун-та. 80 с. С. $33-42$.

\footnotetext{
${ }^{8}$ Большой интерес в этом отношении представляет проект «Прожито», в котором можно ознакомиться с личными дневниками XX столетия. В перспективе планируется публиковать также записные книжки, письма и т. п. См.: О проекте: Электронный ресурс.
} 
Гайдин, Б. Н. (2013b) Образ Гамлета на отечественном экране второй половины XX - начала XXI века // Знание. Понимание. Умение. № 4. С. $170-182$.

Гайдин, Б. Н. (2014а) Неошекспиризация // Знание. Понимание. Умение. № 4. С. 345-354.

Гайдин, Б. Н. (2014b) Неошекспиризация в современной художественной культуре / Б. Н. Гайдин (рук.), К. Н. Кислицын. М. : Изд-во Моск. гуманит. ун-та.

Гайдин, Б. Н. (2015) Разработка программы сравнительного тезаурусного анализа русских переводов произведений У. Шекспира (ответ на доклад Т. Чизмана «Текстовые массивы перевода: версия, вариация, визуализация») // Шекспир в междисциплинарных гуманитарных исследованиях : коллективная монография по материалам Международного научного семинара / ред.-сост. В. С. Макаров, Н. В. Захаров, Б. Н. Гайдин. М. : Изд-во Моск. гуманит. ун-та. 238 с. С. $147-155$.

Гайдин, Б. Н. (2017а) «Коня! Коня! Полцарства за коня!»: вольный перевод шекспировского эптонима в тезаурусе русской культуры // Знание. Понимание. Умение. № 2. С. 183-201. DOI: 10.17805/zpu.2017.2.14

Гайдин, Б. Н. (2017b) «Отелло» Сергея Юткевича в контексте мировой киношекспирианы // Научные труды Московского гуманитарного университета. № 6. C. 88-100. URL: http://journals.mosgu.ru/trudy/article/view/626 (дата обращения: 30.11.2017). DOI: 10.17805/trudy.2017.6.10

Гайдин, Б. Н. (2017c) Шекспир в кино: национальное и глобальное [Электронный ресурс] // Горизонты гуманитарного знания. № 5. С. 102-117. URL: http://journals.mosgu.ru/ggz/article/view/606 (дата обращения: 30.11. 2017). DOI: $10.17805 /$ ggz.2017.5.9

Гайдин, Б. Н. (2018) Два крылатых выражения У. Шекспира в современной русской литературе // Актуальные проблемы изучения и преподавания англоязычной литературы : сб. мат. Межд. науч. конф., Минский государственный лингвистический университет, 21-23 сентября 2017 г. Минск. (В печати).

Долгов, Н. Н. (1914) К истории шекспировских постановок (По поводу 350-летия со дня рождения великого драматурга) // Театр и искусство. № 16. 20 апреля. С. 362-364.

Загорский, М. Б. (1947) Шекспир в России // Шекспировский сборник, 1947 / редколл.: Г. Н. Бояджиев, М. Б. Загорский, М. М. Морозов. М. : Всероссийское театральное общество. 296 с. С. 57-104.

Захаров, Н. В. (2008а) Рецепция Шекспира в творчестве Сумарокова // Тезаурусный анализ мировой культуры : сб. науч. трудов. Вып. 13 / под общ. ред. Вл. А. Лукова. М. : Изд-во Моск. гуманит. ун-та. С. 74-78. 
Захаров, Н. В. (2008b) Шекспиризм русской классической литературы: тезаурусный анализ / отв. ред. Вл. А. Луков ; Моск. гуманит. ун-т. Ин-т фундамент. и прикл. исследований ; Межд. акад. наук (IAS). М. : Изд-во Моск. гуманит. ун-та. 320 с.

Захаров, Н. В., Гайдин, Б. Н., Макаров, В. С. (2016) Всемирный год Шекспира - 400 лет бессмертия поэта // Знание. Понимание. Умение. № 2. С. 287306. DOI: $10.17805 / \mathrm{zpu} .2016 .2 .26$

Итоги XXV Шекспировских чтений 2014: «Шекспир в русскоанглийском культурном диалоге» (Shakespeare Mirrored: A Look at Cultural Relationship) (2014) [Электронный ресурс] // Информационно-исследовательская база данных «Русский Шекспир». 4 октября. URL: http://russhake.ru/menu/news/12724.html [архивировано в WaybackMachine] (дата обращения: 16.11.2017).

Итоги XXVI Международной научной конференции «Шекспировские чтения 2016: 400 лет бессмертия поэта» (2017) / О. Ю. Анцыферова, Л. С. Артемьева, А. Н. Баранов, А. В. Бартошевич, Б. Н. Гайдин, Н. В. Захаров, И. И. Лисович, Г. М. Кружков, В. С. Макаров, В. А. Мусвик, В. А. Рогатин, В. С. Флорова, Е. Н. Шапинская, Н. В. Шипилова // Знание. Понимание. Умение. № 1. С. 269-297. DOI: 10.17805/zpu.2017.1.24

Клейн, Й. (1993) Русский Буало? (Эпистола Сумарокова «О стихотворстве» в восприятии современников) / пер. Н. Ю. Алексеевой // XVIII век. Сборник 18 / отв. ред. Н. Д. Кочеткова. СПб. : Наука. 418, [3] с. C. $40-58$.

Колосов, С. Н., Касаткина, Л. И. (2005) Судьба на двоих. Воспоминания в диалогах. М. : Молодая гвардия. 368 с.

Лагутина, И. Н. (2017а) «За подлинного Шекспира»: два советских юбилея // Вопросы литературы. № 2. С. 316-379.

Лагутина, И. Н. (2017b) «Колхозники требуют постановок Шекспира...»: шекспировский юбилей 1939 г. и деятельность М. М. Морозова в его подготовке и проведении // Noscere est comparare: Компаративистика в контексте исторической поэтики : К юбилею Игоря Шайтанова : Сб. ст. / отв. ред. и авт. вступ. ст. О. И. Половинкина. М. : Изд-во РГГУ. 496 с. С. 231-248.

Левин, Ю. Д. (1965) Шестидесятые годы // Шекспир и русская культура / под ред. М. П. Алексеева. М. ; Л. : Наука. 823 с. С. 407-543.

Макаров, В. С. и др. (2017) Первое издание «Сонетов» Шекспира в академической серии «Литературные памятники» / Е. А. Первушина, В. С. Флорова, Е. В. Халтрин-Халтурина // Знание. Понимание. Умение. № 4. С. 275-302. DOI: 10.17805/zpu.2017.4.22

Макаров, В. С., Захаров, Н. В., Гайдин, Б. Н. (2015) Шекспир в междисциплинарных гуманитарных исследованиях: итоги первого года семинара 
[Электронный ресурс] // Информационный гуманитарный портал «Знание. Понимание. Умение». № 6 (ноябрь - декабрь). С. 38-55. URL: http://zpujournal.ru/e-zpu/2015/6/Makarov_Zakharov_Gaydin_Shakespeare-Interdisciplinary-Humanities-Research/ [архивировано в WebCite] (дата обращения: 16.11.2017).

Макаров, В. С., Захаров, Н. В., Гайдин, Б. Н. (2016) Шекспиросфера в год четырехсотлетия бессмертия поэта // Знание. Понимание. Умение. № 4. С. 250-256. DOI: 10.17805/zpu.2016.4.24

Национальная премия «Лучшие книги и издательства года - 2015» (2016) [Электронный ресурс] // Литературная газета. 3 марта. № 9 (6544). URL: http://lgz.ru/article/-9-6544-3-03-2016/natsionalnaya-premiya-luchshie-knigi -i-izdatelstva-goda-2015/ [архивировано в WaybackMachine] (дата обращения: 16.11.2017).

O проекте [Электронный ресурс] // Прожито. URL: http://prozhito.org/ about [архивировано в Archive.is] (дата обращения: 30.11.2017).

От редакции (1957) // Шекспир У. Полн. собр. соч. : в 8 т. / под общ. ред. А. А. Смирнова и А. А. Аникста. М. : Искусство. Т. 1.615 с. С. 5-6.

Ратников, К. В. (2011) Шекспировские концепции русских поэтов: к трехсотлетнему юбилею Шекспира в 1864 году // Шекспировские чтения 2006 / редколл.: А. В. Бартошевич (гл. ред.) и др. ; сост. И. С. Приходько. М. : Наука. 468, [1] с. С. 315-332.

Сонеты Шекспира (2014) / У.Шекспир ; в пер. [с англ.] О. Ф. Степанова. 2-е изд., испр. М. : Макс Пресс. 166, [1] с.

СССР и Болгария - навеки вместе (1962) : пребывание советской партийно-правительственной делегации во главе с Первым секретарем ЦК КПСС председателем Совета Министров СССР т. Н. С. Хрущевым в Народной Республике Болгарии, 14-20 мая 1962 г. М. : Госполитиздат. 150 с.

Сумароков, А. П. (1748а) Епистола II // [Сумароков А. П.] Двъ епистолы, Александра Сумарокова. Въ перьвой предлагается о Рускомъ языкъ, а во второй о Стихотворствђ. СПб. : [Печ. при Имп. акад. наук]. 29 с. С. 8-20.

Сумароков, А. П. (1748b) Примъчаніи // [Сумароков А. П.] Двъ епистолы, Александра Сумарокова. Въ перьвой предлагается о Рускомъ языкъ, а во второй о Стихотворствђ. СПб. : [Печ. при Имп. акад. наук]. 29 с. С. 21-29.

Сумароков, А. П. (1957) Эпистола II // Сумароков А. П. Избранные произведения. Л. : Советский писатель. 608 с. С. 115-125. (Библиотека поэта. Большая серия, второе издание).

Уильям Шекспир. Энциклопедия (2015) / сост. и науч. ред. И. О. Шайтанов. М. : Просвещение. 680 с. 
Уильям Шекспир: энциклопедия (подарочное издание) [Электронный pecypc] // Мир энциклопедий. URL: http://encyclopedia.ru/cat/books/book/ 68984/ [архивировано в WaybackMachine] (дата обращения: 30.11.2017).

Урнов, М. В., Урнов, Д. М. (1964) Шекспир: его герой и его время. М. : Наука. 206 с.

Фантастический Шекспир (2016) : сборник / сост. В. В. Балашова, под ред. Д. М. Володихина. Севастополь : Шико Севастополь. 182 с. (Серия «Антология МиФа»).

Федорова, Е. В. (2014) Трагедия Вильяма Шекспира «Гамлет». М. : Новый ключ. $43 \mathrm{c}$.

Чекалов, И. И. (2014) Русский шекспиризм в XX веке : [посвящается 450-летию со дня рождения Уильяма Шекспира]. М. : Река времени. 278 с.

Чернышова, Р. Н. Долгов Николай Николаевич. К 90-летию со дня смерти [Электронный ресурс] // Музей, мемориальный и природный заповедник Щелыково. URL: http://museumschelykovo.ru/products/item.aspx?pid= 137 [архивировано в WaybackMachine] (дата обращения: 15.11.2017).

Чизман, Т. (2015) Массивы переводов и их цифровое истолкование // Шекспир в междисциплинарных гуманитарных исследованиях : коллективная монография по материалам Международного научного семинара / ред.сост. В. С. Макаров, Н. В. Захаров, Б. Н. Гайдин. М. : Изд-во Моск. гуманит. ун-та. 238 с. С. $114-146$.

Шекспир (1964) : библиография русских переводов и критической литературы на русском языке, 1748-1962 / сост. И. М. Левидова. М. : Книга. 711 c.

Шекспир в междисциплинарных гуманитарных исследованиях (2015) : коллективная монография по материалам Международного научного семинара / ред.-сост. В. С. Макаров, Н. В. Захаров, Б. Н. Гайдин. М. : Изд-во Моск. гуманит. ун-та. 238 с.

Шекспир в мировой литературе (1964) : сб. ст. / общ. ред. Б. Г. Реизова. М. ; Л. : Художественная литература [Ленинградское отделение]. 383 с.

Шекспир и музыка (1964) : сб. ст. / Ленингр. гос. ин-т театра, музыки и кинематографии им. Н. К. Черкасова ; отв. ред. Л. Н. Раабен. Л. : Музыка. 320 c.

Шекспир и русская культура (1965) / под ред. М. П. Алексеева. М. ; Л. : Наука. 823 с.

Шекспир, В. (1936-1950) Полн. собр. соч. : в 8 т. / под общ. ред. С. С. Динамова, А. А. Смирнова. М. ; Л. : Academia / Гослитиздат.

Шекспир, В. (2014a) Король Лир ; Монолог Гамлета («Гамлет» — Акт III; Сцена 1) / В. Шекспир ; Е. П. Парамонов, новое прочтение, анализ, рас- 
шифровка и поэтический перевод оригиналов 400-летней давности. М. : Сам Полиграфист. 397 с.

Шекспир, У. (1957-1960) Полн. собр. соч. : в 8 т. / под общ. ред. А. А. Смирнова и А. А. Аникста. М. : Искусство.

Шекспир, У. (2014b) Переводы сонетов Шекспира (подстрочные и поэтические) / пер. В. Я. Тяптин. Ижевск : Проект. 339 с.

Шекспир, У. (2014c) Ричард III : поэтический перевод-интерпретация / У. Шекспир ; пер. А. А. Сагратяна. М. : [б. и.]. 134 с.

Шекспир, У. (2014d) Король Лир : поэтический перевод-интерпретация / У. Шекспир ; пер. А. А. Сагратяна. М. : [б. и.], 2014. 134, [1] с.

Шекспир, У. (2014е) Отелло : поэтический перевод-интерпретация / У. Шекспир ; пер. А. А. Сагратяна. М. : [б. и.]. 134, [1] с.

Шекспир, У. (2014f) Джульетта и Ромео : поэтический переводинтерпретация / У. Шекспир; ; пер. А. А. Сагратяна М. : [б. и.]. 110, [1] с.

Шекспир, У. (2014g) Трагедия о Гамлете, принце Дании : в 5 актах / У. Шекспир ; [пер. с англ. И. К. Тюриковой. М. : Тип. «Ваш формат». 288, [1] c.

Шекспир, У. (2016) Сонеты / изд. подгот. А. Н. Горбунов, В. С. Макаров, Е. А. Первушина, В. С. Флорова, Е. В. Халтрин-Халтурина ; отв. ред. А. Н. Горбунов. М. : Наука. 884 с. (Литературные памятники).

Шифрина, А. Н. (1975) Вильям Шекспир в творчестве советских художников театра : альбом. М. : Советский художник. 218 с.

Шнеер, А. Я. (1963) Долгов, Николай Николаевич // Театральная энциклопедия : в 5 т. / глав. ред. А. П. Марков. М. : Советская энциклопедия. Т. 2: Гловацкий - Кетуракис. 1216 стб. Стб. 473.

XXV Шекспировские чтения 2014 : «Шекспир в русско-английском культурном диалоге» (25th Shakespeare Readings 2014 : Shakespeare Mirrored: A Look at Cultural Relationship) (2014) : Сборник аннотаций докладов. М. : Изд-во Моск. гуманит. ун-та. 203 с.

XXVI Шекспировские чтения 2016 : 400 лет бессмертия поэта (26th Shakespeare Readings 2016 : 400 Years of Immortality) (2016) : сб. аннотаций докладов. М. : Изд-во Моск. гуманит. ун-та. 128 с.

About Play On! [Электронный ресурс] // Play On! — Oregon Shakespeare Festival. URL: https://playonosf.org/about/ [архивировано в WaybackMachine] (дата обращения: 16.11.2017).

Burnett, M. (2007) Filming Shakespeare in the global marketplace. Basingstoke ; N. Y. : Palgrave Macmillan. xi, 227 p.

Cheesman, T. (2015) Reading originals by the light of translations // Shakespeare Survey. Vol. 68. P. 87-98. 
Dobson, M. (1992) The making of the national poet: Shakespeare, adaptation and authorship, 1660-1769. Oxford : Clarendon Press. viii, 266 p.

Foreign accents: Brazilian readings of Shakespeare (2002) / ed. by A. da Cunha Resende ; language consultant: Th. LaBorie Burns. Newark : University of Delaware Press ; L. : Associated University Presses. 230 p.

Global Shakespeare (2012) / ed. by J. M. González, R. Wilson, C. Bellis. Alicante : Universidad de Alicante. 418 p. (Alicante Journal of English Studies / Revista Alicantina de Estudios Ingleses, no. 25).

Huang, A. (2009) Chinese Shakespeares: Two centuries of cultural exchange. N. Y. : Columbia University Press. xi, $350 \mathrm{p}$.

Huang, A. (2013) Global Shakespeares as methodology // Shakespeare: Journal of the British Shakespeare Association. Vol. 9. Issue 3. P. 273-290.

India's Shakespeare: Translation, interpretation, and performance (2005) / ed. by P. Trivedi, D. Bartholomeusz. Newark : University of Delaware Press. 303 p.

Kishi, T., Bradshaw, G. (2005) Shakespeare in Japan. L. : Continuum. 153 p.

Native Shakespeares: Indigenous appropriations on a global stage (2008) / ed. by C. Dionne, P. Kapadia. Aldershot ; Burlington, VT : Ashgate. ix, 247 p.

Oregon Shakespeare Festival's Play On! Translation project (2015) [Электронный ресурс] // Shakespeareances.com. August 18. URL: http://shakespeareances.com/wherewill/news/OSF_Translation_Project-151019.html [архивировано в WaybackMachine] (дата обращения: 16.11.2017).

Orkin, M. (2005) Local Shakespeares: Proximations and power. L. ; N. Y. : Routledge. $x, 220 \mathrm{p}$.

Performing Shakespeare in India: Exploring Indianness, literatures and cultures (2016) / ed. by S. Panja, B. Moitra Saraf. New Delhi : India SAGE Publications India Pvt Ltd. vii, 268 p.

Shakespeare and Ireland: History, politics, culture (1997) / ed. by M. Thornton Burnett and R. Wray. L. : MacMillan ; N. Y. : St. Martin's Press. xii, $264 \mathrm{p}$.

Shakespeare and national culture (1997) / ed. by J. J. Joughin. Manchester ; N. Y. : Manchester University Press. ix, 351 p.

Shakespeare and Spain (2002) / ed. by J. Manuel González, H. Klein. Lewiston, NY : Edwin Mellen Press. 544 p.

Shakespeare in the new Europe (1994) / ed. by M. Hattaway, B. Sokolova, D. Roper. Sheffield : Sheffield Academic Press. 384 p.

Shakespeare on the global stage: Performance and festivity in the Olympic year (2015) / ed. by P. Prescott, E. Sullivan. L. ; N. Y. : Bloomsbury Arden Shakespeare, an imprint of Bloomsbury Publishing. xvii, $356 \mathrm{p}$. 
Shakespeare, Italy, and transnational exchange: Early modern to present (2017) / ed. by Ch. Stamatakis, E. De Francisci. N. Y. : Routledge. (Routledge Studies in Shakespeare, 20).

Shakespeare: World views (1996) / ed. by H. Kerr, R. Eaden, M. Mitton. Newark, DE : University of Delaware Press ; L. ; Cranbury, NJ : Associated University Presses. 258 p.

South African essays on 'universal' Shakespeare (2016) / ed. by Ch. Thurman. Abingdon, Oxon : Routledge. xxi, 208 p.

The Shakespearean International Yearbook. Vol. 12: Special section (2012) / general editors: T. Bishop, A. Huang ; editor emeritus: G. Bradshaw ; special guest editor: S. Chaudhuri. Farnham, Surrey : Ashgate. ix, 252 p.

The Shakespearean International Yearbook. Vol. 8: Special section, European Shakespeares (2008) / general editors G. Bradshaw, T. Bishop ; special guest editors: T. Hoenselaars, C. Calvo. Aldershot : Ashgate. vi, 303 p.

World-wide Shakespeares: Local appropriations in film and performance (2005) / ed. by S. Massai. L. ; N. Y. : Routledge. xii, 199 p.

26th Shakespeare Readings 2016 : 400 years of immortality (2016) : Paper abstracts. Moscow : Moscow University for the Humanities Publ. 111 p.

Дата поступления: 30.11.2017 2.

Гайдин Борис Николаевич - кандидат философских наук, начальник Научно-исследовательского отдела цифровых технологий Института фундаментальных и прикладных исследований Московского гуманитарного университета, член-корреспондент Международной академии наук (IAS, Инсбрук). Адрес: 111395, Россия, г. Москва, ул. Юности, 5, корп. 6. Тел.: +7 (499) 374-59-30. Эл. адрес: bngaydin@ mosgu.ru

Gaydin Boris Nikolaevich, Candidate of Philosophy, Head, Research Department of Digital Technologies, Institute of Fundamental and Applied Studies, Moscow University for the Humanities; Associate Member, International Academy of Science (IAS, Innsbruck). Postal address: Bldg. 6, 5 Yunosti St., 111395 Moscow, Russian Federation. Tel.: +7 (499) 374-59-30. E-mail: bngaydin@ mosgu.ru 
Для цุитирования:

Гайдин Б. Н. Шекспир в кино: национальное и глобальное [Электронный ресурс] // Горизонты гуманитарного знания. 2017. № 6. С. 47-71. URL: http://journals.mosgu.ru/ggz/article/view/640 (дата обращения: дд.мм.гггг). DOI: 10.17805/ggz.2017.6.4 